\title{
Int7G24A polymorphism (rs334354) and cancer risk
}

Xiaolong Liu, Yuxi Shan, Boxin Xue

Urology Department, the Second Affiliated Hospital of Soochow University, Suzhou, China

Submitted: 29 February 2012

Accepted: 9 July 2012

Arch Med Sci 2013; 9, 1: 3-7

DOI: 10.5114/aoms.2013.33341

Copyright $\odot 2013$ Termedia \& Banach

\author{
Corresponding author: \\ Prof. Yuxi Shan \\ Urology Department \\ the Second Affiliated Hospital \\ of Soochow University \\ 1055 Sanxiang Road \\ Suzhou 215004, China \\ Phone: 86-13814850558 \\ E-mail: shanyuxi1002@126.com
}

\begin{abstract}
Introduction: The transforming growth factor $\beta$ (TGF- $\beta$ ) signaling system plays an important role in carcinogenesis. Alteration of TGF- $\beta$ receptors is a potential mechanism in the development and progression of human cancers. Several studies have investigated the association between TGFBR1 gene Int7G24A and cancer risk, but the results are still inconclusive, so a meta-analysis is needed to verify the association.

Material and methods: We carried out a literature search using the PubMed database (up to January 2012) to identify all papers that investigated the association between the Int7G24A polymorphism (rs334354) and cancer risk. The inclusion criteria were: (1) evaluation of the Int7G24A polymorphism and cancer risk, (2) case-control studies, (3) sufficient published data about genotype frequency. Also the strength of the association between Int7G24A polymorphism and cancer was measured by odds ratio (OR), which was calculated according to the method of Woolf. A $\chi^{2}$-based $Q$ statistic test was performed to assess the between-study heterogeneity.

Results: There are 10 studies including 2398 cases and 3465 controls in the research. Our results indicate that the TGFBR1 gene Int7G24A polymorphism is associated with cancer risk (A vs. $G$ : $O R=1.35,95 \% \mathrm{Cl}=1.10-1.66, \mathrm{~A} / \mathrm{A}+\mathrm{G} / \mathrm{A}$ vs. $\mathrm{G} / \mathrm{G}: \mathrm{OR}=1.34,95 \% \mathrm{Cl}=1.05-1.72$ ).

Conclusions: This meta-analysis suggests that the TGFBR1 gene Int7G24A polymorphism might be associated with an increased risk of cancer.
\end{abstract}

Key words: TGFBR1, Int7G24A polymorphism, cancer risk, meta-analysis.

\section{Introduction}

The transforming growth factor $\beta$ (TGF- $\beta$ ) signaling system plays an important role in carcinogenesis [1]. Alteration of TGF- $\beta$ receptors is a potential mechanism of TGF- $\beta$ growth inhibitory signals and the development and progression of human cancers [2]. The TGFBR1 gene is located on chromosome 9 [3]. One commonly studied polymorphism of TGFBR1 is Int7G24A (rs334354), which could lead to a $G$ to A substitution in intron $7[4,5]$. Several studies have investigated the association between Int7G24A and cancer risk, and a meta-analysis by Zhang 6 years ago found that Int7G24A was a low-penetrance tumor susceptibility allele that predisposes to carcinogenesis of non-small cell lung cancer (NSCLC), kidney and bladder malignancies [6]. However, there have been more studies about it, and the results are still inconclusive. So we performed a meta-analysis again to derive a more precise estimation of this relationship. 
Table I. Characteristics of case-control studies included in Int7G24A polymorphism and cancer risk

\begin{tabular}{|c|c|c|c|c|c|c|c|c|c|c|}
\hline \multirow[t]{2}{*}{ No. } & \multirow[t]{2}{*}{ First author } & \multirow[t]{2}{*}{ Year } & \multirow[t]{2}{*}{ Country } & \multirow[t]{2}{*}{ Cancer types } & \multicolumn{3}{|c|}{ Cases } & \multicolumn{3}{|c|}{ Controls } \\
\hline & & & & & $\mathrm{G} / \mathrm{G}$ & $\mathrm{G} / \mathrm{A}$ & $\mathrm{A} / \mathrm{A}$ & $\mathrm{G} / \mathrm{G}$ & $\mathrm{G} / \mathrm{A}$ & $\mathrm{A} / \mathrm{A}$ \\
\hline 1 & Chen [4] & 1999 & Holland & Cervical cancer & 9 & 7 & 0 & 24 & 12 & 2 \\
\hline 2 & Zhang [5] & 2003 & China & Non-small cell lung cancer & 18 & 24 & 11 & 31 & 52 & 6 \\
\hline 3 & Chen [11] & 2004 & USA & Renal cell carcinoma & 46 & 36 & 4 & 81 & 32 & 0 \\
\hline 4 & Chen [11] & 2004 & USA & Transitional cell carcinoma & 33 & 28 & 4 & 81 & 32 & 0 \\
\hline 5 & Chen [12] & 2006 & USA & Breast cancer & 120 & 92 & 11 & 113 & 37 & 3 \\
\hline 6 & Song [13] & 2007 & Sweden & Breast cancer & 500 & 238 & 29 & 559 & 265 & 29 \\
\hline 7 & Lundin [14] & 2009 & Sweden & Colorectal cancer & 135 & 67 & 12 & 559 & 265 & 29 \\
\hline 8 & Castillejo [15] & 2009 & Spain & Colorectal cancer & 296 & 178 & 30 & 333 & 156 & 15 \\
\hline 9 & Foresti [16] & 2010 & Sweden & Colorectal cancer & 220 & 68 & 14 & 382 & 179 & 20 \\
\hline 10 & $\mathrm{Hu}[17]$ & 2010 & China & Osteosarcoma & 100 & 57 & 11 & 115 & 48 & 5 \\
\hline
\end{tabular}

\section{Material and methods}

\section{Search strategy}

We carried out a literature search using the PubMed database (up to January 2012) to identify all papers that investigated the association between the Int7G24A polymorphism (rs334354) and cancer risk in all ethnic groups, using combinations of the search terms "Int7G24A" and "polymorphism" and "cancer". We evaluated the titles and abstracts of all relevant publications, but excluded abstracts, case reports, editorials, and review articles.

\section{Inclusion criteria}

The inclusion criteria were: (1) evaluation of the Int7G24A polymorphism and cancer risk, (2) casecontrol studies, (3) sufficient published data about genotype frequency.

\section{Data extraction}

We followed a standard protocol for data extraction. The following data were collected from each study: the first author, publication date, country, ethnicity of the study population, cancer types, the number of cases and controls, and numbers of every genotype, respectively.

\section{Statistical analysis}

The strength of the association between Int7G24A polymorphism and cancer was measured by the

Table II. Summary ORs and $95 \%$ CI of TGFBR1 polymorphism and cancer risk

\begin{tabular}{|lccc|}
\hline Analysis model & OR & $95 \% \mathrm{Cl}$ & Value of $p$ \\
\hline A vs. G & 1.35 & $1.10-1.66$ & 0.004 \\
\hline A/A+G/A vs. G/G & 1.34 & $1.05-1.72$ & 0.02 \\
\hline
\end{tabular}

Value of $p$ for heterogeneity odds ratio (OR), which was calculated according to the method of Woolf [7]. A $\chi^{2}$-based Q statistic test was performed to assess the between-study heterogeneity [8]. Owing to the low power of the statistic, heterogeneity was considered significant for $p<0.10$. A fixed effects model using the MantelHaenszel method or a random-effects model using the DerSimonian and Laird method was used to pool the results [9]. The significance of the pooled OR was determined by the Z-test. Publication bias was investigated by using a funnel plot, in which the standard error of log (OR) of each study was plotted against its log (OR). Funnel plot asymmetry was further assessed by the method of Egger's linear regression test [10].

\section{Results}

Based on our search criteria, 9 publications were identified [4, 5, 11-17]. Among them, 1 publication included 2 case-control studies [11]. Hence, 9 publications including 10 studies were included in the final meta-analysis. In total, these studies included 2398 cases and 3465 controls. There were 2 studies concerning breast cancer, 3 concerning colorectal cancer, 1 concerning non-small lung cancer, 1 concerning renal cell carcinoma, 1 concerning transitional cell carcinoma, and 1 concerning osteosarcoma. All studies presented the numbers of $G / G$, $G / A$, and $A / A$ genotypes separately. The characteristics of these studies are listed in Table I.

\section{Meta-analysis results}

The main results of this meta-analysis and the heterogeneity test are shown in Table II. When all 10 studies were pooled into the meta-analysis, significantly elevated cancer risk was associated with Int7G24A of TGFBR1 (A vs. G: $O R=1.35,95 \% \mathrm{Cl}=$ 1.10-1.66, Figure 1; $A / A+G / A$ vs. $G / G: O R=1.34$, $95 \% \mathrm{Cl}=1.05-1.72$, Figure 2). 


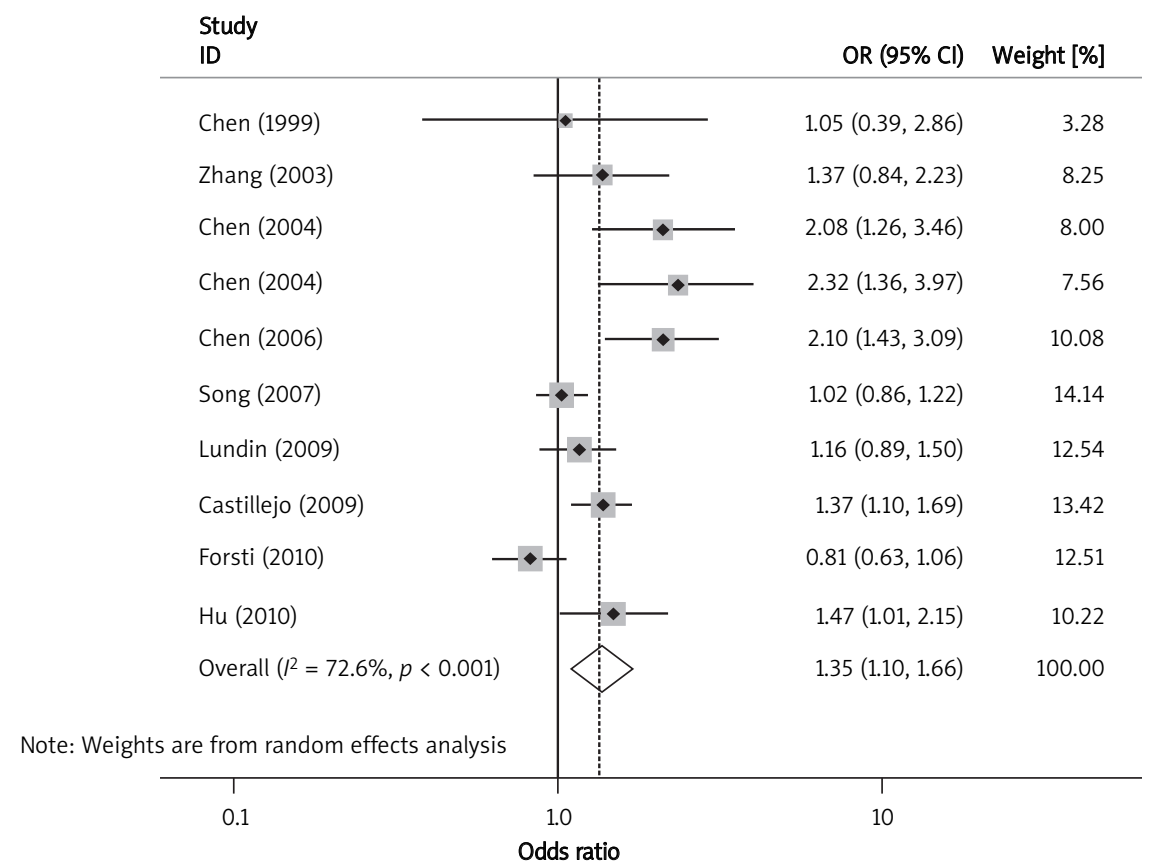

Figure 1. Forest plot for allele contrast (A vs. G) of the Int7G24A polymorphism in cancers

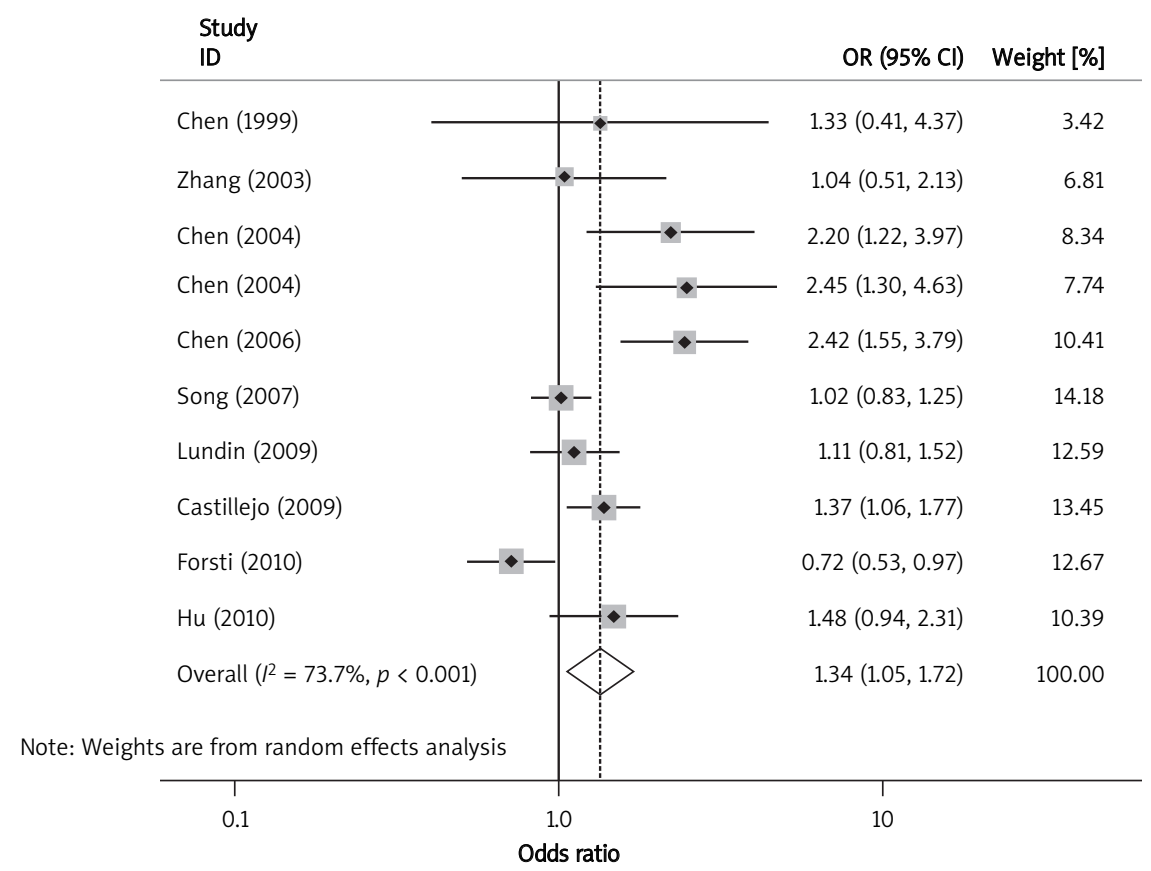

Figure 2. Forest plot for variant genotypes (A/A+G/A vs. G/G) of the Int7G24A polymorphism in cancers

\section{Sensitivity analysis}

A single study involved in the meta-analysis was deleted each time to reflect the influence of the individual data-set on the pooled ORs. None of the results were materially altered (data not shown).

\section{Publication bias}

The shapes of the funnel plots did not reveal obvious asymmetry (figures not shown). Also the results of Egger's test did not suggest any evidence of publication bias ( $p=0.10$ for A vs. G, $p=0.15$ for $A / A+G / A$ vs. $G / G)$.

\section{Discussion}

Cancer is one of the leading causes of mortality worldwide now. However, the mechanism of carcinogenesis, which may be triggered by genetic as well as environmental factors, is still not fully under- 
stood [18]. In recent years, many candidate genes have been reported to be involved in cancer susceptibility, including p53 [19], SPINK1 [20], TGF- $\beta$ [1], and so on.

We all know the TGF- $\beta$ signaling pathway is implicated in the pathogenesis of carcinogenesis. In this pathway, TGF- $\beta$ binds directly to TGFBR2, and is then recognized by TGFBR1, which is phosphorylated and activated by TGFBR2 [21]. Upon binding of TGF- $\beta$ to its receptors, receptor-regulated $\mathrm{Smad} 2 / 3$ proteins become phosphorylated and associate with Smad4, and then translocate to the nucleus, where they regulate transcription of specific genes [22,23].

TGFBR1 is crucial in the development and progression of cancer. A number of studies were reported to assess the effects of TGFBR1 polymorphism (TGFBR1*6A) on cancer risk [24], and this relationship was confirmed in a recent meta-analysis [25]. With respect to another single-nucleotide polymorphism (SNP), Int7G24A (rs334354), a metaanalysis by Zhang in 2005 showed that it is associated with increased cancer risk [6]. But there have been more studies about it, and the results are still inconclusive. Therefore, a meta-analysis was needed to confirm the association of the Int7G24A polymorphism with cancer risk.

Our pooled results, which included 2398 cases and 3465 controls, concerning seven kinds of cancers, indicated that the Int7G24A polymorphism was associated with cancer risk. The Int7G24A allele contrast (A) has a $35 \%$ increased risk of cancer, and the Int7G24A variant genotypes (both heterozygous $\mathrm{G} / \mathrm{A}$ and homozygous $\mathrm{A} / \mathrm{A}$ ) have a $34 \%$ increased risk of cancer.

In conclusion, considering the limited studies and population numbers included in the metaanalysis, and the fact that studies with negative results are less likely to be published, further studies are encouraged to better identify these findings.

Despite these limitations, this meta-analysis confirms that Int7G24A polymorphism is associated with increased cancer risk.

\section{References}

1. Elliott RL, Blobe GC. Role of transforming growth factor beta in human cancer. J Clin Oncol 2005; 23: 2078-93.

2. Levy L, Hill CS. Alterations in components of the TGF-beta superfamily signaling pathways in human cancer Cytokine Growth Factor Rev 2006; 17: 41-58.

3. Johnson DW, Qumsiyeh M, Benkhalifa M, Marchuk DA. Assignment of human transforming growth factor-beta type I nd type III receptor genes (TGFBR1 and TGFBR3) to 9q33-q34 and 1p32-p33, respectively. Genomics 1995; 28: 356-7.

4. Chen T, de Vries EG, Hollema H, et al. Structure alteration of transforming growth factor-beta receptor genes in human cervical carcinoma. Int J Cancer 1999; 82: 43-51.
5. Zhang HT, Fei QY, Chen F, et al. Mutational analysis of the transforming growth factor beta receptor type I gene in primary non-small cell lung cancer. Lung Cancer 2003; 40: 281-7.

6. Zhang HT. Int7G24A variant of the TGFBR1 gene and cancer risk: a meta-analysis of the three case-control studies. Lung Cancer 2005; 49: 419-20.

7. Woolf B. On estimating the relationship between blood group and disease. Ann Human Genet 1955; 19: 251-3.

8. Lau J, loannidis JP, Schmid CH. Quantitative synthesis in systematic reviews. Ann Intem Med 1997; 127: 820-6.

9. Petitti D. Meta-analysis, decision analysis, and costeffectiveness analysis. Oxford University Press, New York 1994.

10. Egger M, Davey Smith G, Schneider M, Minder C. Bias in meta-analysis detected by a simples, graphical test. BMJ 1997; 315: 629-34.

11. Chen $T$, Jackson $C$, Costello $B$, et al. An intronic variant of the TGFBR1 gene is associated with carcinomas of the kidney and bladder. Int J Cancer 2004; 112: 420-5.

12. Chen T, Jackson CR, Link A, et al. Int7G24A variant of transforming growth factor-beta receptor type 1 is associated with invasive breast cancer. Clin Cancer Res 2006; 12: 392-7.

13. Song B, Margolin S, Skoglund J, et al. TGFBR1* 6 A and Int7G24A variants of transforming growth factor-beta receptor 1 in Swedish familial and sporadic breast cancer. Br J Cancer 2007; 97: 1175-9.

14. Skoglund Lundin J, Vandrovcova J, Song B, et al. TGFBR1 variants TGFBR1*6A and Int7G24A are not associated with an increased familial colorectal cancer risk. Br J Cancer 2009; 100: 1674-9.

15. Castillejo A, Mata-Balaguer T, Guarinos C, et al. The Int7G24A variant of transforming growth factor-beta receptor type 1 is a risk factor for colorectal cancer in the Spanish population: a case-control study. BMC Cancer 2009; 9: 406.

16. Forsti A, Li X, Wagner K, et al. Polymorphisms in the transforming growth factor beta 1 pathway in relation to colorectal cancer progression. Gene Chromosomes Cancer 2010; 49: 270-81.

17. Hu YS, Pan Y, Li WH, Zhang Y, Li J, Ma BA. Int7G24A variant of transforming growth factor-beta receptor 1 is associated with osteosarcoma susceptibility in a Chinese population. Med Oncol 2011; 28: 622-5.

18. Smolińska K, Paluszkiewicz P. Risk of colorectal cancer in relation to frequency and total amount of red meat consumption. Systematic review and meta-analysis. Arch Med Sci 2010; 6: 605-10.

19. El-Din HG, Ghafar NA, Saad NE, Aziz M, Rasheed D, Hassan EM. Relationship between codon 249 mutation in exon 7 of p53 gene and diagnosis of hepatocellular carcinoma. Arch Med Sci 2010; 6: 348-55.

20. Gasiorowska A, Talar-Wojnarowska R, Czupryniak L, et al. Prevalence of the N34S mutation of SPINK1 (serine protease inhibitor, Kazal type 1) in patients with chronic pancreatitis and pancreatic cancer. Prz Gastroenterol 2010; 5: 214-21.

21. Heldin CH, Miyazono K, ten Dijke P. TGB-beta signaling from cell membrane to nucleus through SMAD proteins. Nature 1997; 390: 465-71.

22. Attisano L, Wrana JL. Signal transduction by the TGF-beta superfamily. Science 2002; 296: 1646-7.

23. Shi Y, Massague J. Mechanisms of TGF-beta signaling from cell membrane to the nucleus. Cell 2003; 113: 685-700. 
24. Zhang HT, Zhao J, Zheng SY, Chen XF. Is TGFBR1*6A really associated with increased risk of cancer? J Clin Oncol 2005; 23: 7743-4.

25. Liao RY, Mao C, Qiu LX, Ding H, Chen Q, Pan HF. TGFBR1*6A/9A polymorphism and cancer risk: a metaanalysis of 13662 cases and 14147 controls. Mol Biol Rep 2010; 37: 3227-32. 